\title{
AVALIAÇÃO FITOQUÍMICA, ANTIBACTERIANA E MODULATÓRIA DOS EXTRATOS METANÓLICO E HEXÂNICO DA FOLHA DE Eugenia uniflora L.
}

\section{PHYTOCHEMICAL, ANTIBACTERIAL AND MODULATORY EVALUATION OF THE METANOLIC AND HEXANIC EXTRACTS OF THE LEAF OF Eugenia uniflora L.}

\author{
Francisca Flaviane Pereira dos Santos ${ }^{1}$, Livia Maria Garcia Leandro², Rakel Olinda \\ Macedo², Tássia Thaís de Alencar Martins Guedes², Maria Karollyna do Nascimento \\ Silva², Maria Bethânia de Sousa Ferreira², Dárcio Luiz de Sousa Junior³, Phablo \\ Wemeson Figueredo de Sousa ${ }^{4}$, Michele Albuquerque Jales de Carvalho ${ }^{5}$, Talita \\ Matias Barbosa ${ }^{5}$, Pedro Everson Alexandre de Aquino ${ }^{5}$
}

1 - Graduação em Biomedicina- Centro Universitário Doutor Leão Sampaio

2 - Docente- Centro Universitário Doutor Leão Sampaio

3 - Mestrando-Programa de Pós-Graduação em Química Biológica, Universidade Regional do Cariri (URCA)

4 - Graduação em Medicina- Faculdade de Medicina Estácio de Juazeiro do Norte (FMJ)

5 - Doutorando- Programa de Pós-Graduação em Farmacologia, Universidade Federal do Ceará (UFC)

Autor para correspondência: pedroeverson.alexandre@gmail.com

\section{RESUMO:}

Eugenia uniflora L. pertence à família Myrtaceae, no qual é originária da mata atlântica brasileira, é popularmente conhecida como pitangueira sendo muito utilizada no combate de diarréias, reumatismo, febres, distúrbios gastrointestinais, na atividade anti-inflamatória, antimicrobiana e também atua na estratégia hipoglicemiante. Este estudo tem como principal objetivo avaliar a prospecção fitoquímica, antibacteriana e moduladora dos extratos metanólico e hexânico das folhas de E. uniflora L. frente a cepas de bactérias padrões e multirresistentes. Para a análise da atividade antibacteriana dos extratos metanólico e hexânico, foi realizado o teste de microdiluição em caldo para determinação da concentração inibitória mínima (CIM), e a modulação de aminoglicosídeos por meio de gentamicina e amicacina. Os resultados obtidos da CIM pelas bactérias Escherichia coli e Staphylococcus aureus, foram $\geq 1024 \mu \mathrm{g} / \mathrm{mL}$ para os dois extratos. Na modulação, houve antagonismo tanto para o extrato metanólico, quanto para o hexânico, frente as bactérias multirresistentes SA 358 e EC 27. Desse modo é essencial realizar novos estudos sobre os produtos naturais utilizados pela população e suas ações sobre os antimicrobianos testados, pois podem apresentar os mesmos efeitos como este, em que, reduz o efeito do antibiótico e assim podendo dificultar o tratamento de diversas doenças.

Palavras-chave: Eugenia uniflora L. Produtos naturais. Resistência bacteriana.

\section{ABSTRACT}

Eugenia uniflora L. belongs to the Myrtaceae family, which originates from the Brazilian Atlantic forest, is popularly known as pitangueira and is widely used in the fight against diarrhea, rheumatism, fevers, gastrointestinal disorders, anti-inflammatory activity, antimicrobial activity hypoglycaemic. This study has as main objective to evaluate the phytochemical, antibacterial and modulatory prospection of the methanolic and hexane extracts of $E$. uniflora L. leaves against strains of standard and multiresistant bacteria. For the analysis of the antibacterial activity of the methanolic and hexanic extracts, the broth 
microdilution test was performed to determine the minimum inhibitory concentration (MIC), and the aminoglycoside modulation by means of gentamicin and amikacin. The results obtained from the MIC by the bacteria Escherichia coli and Staphylococcus aureus were $\geq$ $1024 \mu \mathrm{g} / \mathrm{mL}$ for the two extracts. In the modulation, there was antagonism for both methanolic and hexanic extract against the multiresistant bacteria SA 358 and EC 27. Thus, it is essential to carry out new studies on the natural products used by the population and their actions on the tested antimicrobials, since they can present the same effects as this, in which, it reduces the effect of the antibiotic and thus may make it difficult to treat various diseases.

Key words: Eugenia uniflora L. Natural products. Bacterial resistance.

\section{INTRODUÇÃO}

O uso de plantas medicinais tem sido feito por várias gerações ao longos do anos, estas sendo utilizadas paras os mais variados tratamentos de muitos tipos de doenças, tornando-se as principais fontes de terapias medicamentosas em enfermidades humanas (CARVALHO, 2011). A maior vantagem do uso desses produtos naturais é a fácil acessibilidade, sendo encontrados em muitos locais e baixo custo, deste modo utilizado em todas as populações em todo o mundo (MARINHO, SILVA e ANDRADE, 2010).

Os apelos pelo consumo de produtos à base de fontes naturais aumentam a cada dia, isso porque no Brasil o consumo desses recursos é reduzido ou o conhecimento sobre suas propriedades farmacológicas é baixo (JUNIOR, PINTO e MACIEL, 2005). Dentre as plantas com propriedade medicinais destaca-se a Eugenia uniflora L. da família Myrtaceae, em que é originária da mata atlântica Brasileira, possui grande potencial econômico de exploração para a região do Nordeste (BEZERRA et al., 2004), no qual é eficaz para o tratamento de várias enfermidades (SOARES, 2011), sua ação se dá através do consumo de suas folhas e frutos (AURICCHIO, 2007), pois são nestes que há fonte de nutrientes presentes (BAGETTI et al., 2009).

Suas folhas tem importante ação antidiarreica, antirreumática e anti-inflamatória (ASSIS, 2012). Estando totalmente relacionada ao tratamento de diversos distúrbios, como os gastrointestinais, atua na estratégia hipoglicemiante (BEZERRA et al., 2004), por inibir as enzimas $\mathrm{x}$ - glicosidase, sucrase e maltase e tem atividade antimicrobiana por conter muitos constituintes químicos com esta ação nesta parte da planta (AURICCHIO, 2003).

Neste contexto, a bactéria Staphylococcus aureus que pode causar desde uma simples infecção ou até mesmo infecções mais graves como síndrome do choque tóxico, meningite, pneumonia, endocardite, septicemia e outras (SANTOS et al., 2007). Já as cepas de Escherichia coli apresenta maior incidência principalmente em infecções urinárias com potencialidade em causar doenças, como meningite em neonatal, septicemia, ITU 
(NASCIMENTO, 2013), e a mais comum, que é a diarreia do viajante, sendo esta uma diarreia aquosa (SOUZA, 2002).

A principal causa do surgimento da resistência bacteriana é devido ao mau uso de antimicrobianos (SOUZA, 2002; ZIMERMAN, 2010). Sendo de grande importância desenvolver novos antibióticos em que as bactérias não sejam capazes de desenvolver resistência, porém o mesmo tem a necessidade de ter novos mecanismos de ação para que essa resistência não permaneça, e para que esse desenvolvimento possa ocorrer (ROCHA et al., 2011), tem como fator importante o estudo com produtos naturais, em que deve ser realizado através da avaliação de testes a partir de plantas medicinais, no qual vai em busca de seus benefícios em relação aos mecanismos de ação (MENDONÇA et al., 2016).

Portanto, este estudo visou determinar a avaliação da prospecção fitoquímica, antibacteriana e modulatória dos extratos metanólico e hexânico da folha de Eugenia uniflora L. frente a cepas de bactérias padrões e multirresistentes.

\section{MATERIAL E MÉTODOS}

\subsection{Material Vegetal}

Folhas da Eugenia uniflora L. coletadas no município de Brejo Santo, Ceará, Brasil. O material vegetal foi identificado e uma exsicata da espécie foi depositada, com o no 12.361, no Herbário Dárdano Andrade Lima da Universidade Regional do Cariri (URCA).

\subsection{Preparação dos Extratos Metanólico e Hexânico}

Para preparação e obtenção dos extratos foram coletadas folhas que ainda frescas passaram pelo processo de trituração, tendo assim o aumento da superfície de contato, em seguida foram acondicionadas em recipientes individualizados contendo solvente (Metanol P.A. ou Hexano P.A.) suficiente para submergir todo material vegetal por $72 \mathrm{~h}$, sendo após esse período, filtrado em papel filtro e concentrado em condensador rotativo a vácuo e ultrathermal banho (BRASILEIRO et al., 2006).

\subsection{Prospecção Fitoquímica}

Os testes fitoquímicos foram realizados segundo a metodologia de Matos (1997), 
no qual foram submetidos com a função de detectar os metabólitos secundários presentes nos extratos. Para obter o resultado, foi observado a mudança de cor e a formação do precipitado, após a adição de reagentes específicos como o NAOH (Hidróxido de sódio e HCL (Ácido Clorídrico) (FIRMO et al., 2014).

\subsection{Preparo da solução inicial e das soluções de teste.}

No preparo da solução inicial, o extrato foi solubilizado em dimetilsulfóxido (DMSOMerck, Darmstadt, Alemanha), foram observadas as seguintes proporções: $10 \mathrm{mg}$ de extrato solubilizados em $1 \mathrm{~mL}$ de DMSO, para obter uma concentração inicial de $10 \mathrm{mg} / \mathrm{mL}$. Em seguida, esta solução foi diluída em água destilada atingindo concentração de extrato de $1024 \mu \mathrm{g} / \mathrm{mL}$ e reduzindo a concentração de DMSO para 10\% e a partir desta, realizouse diluições seriadas 1:2, durante o teste microdiluição, obtendo-se as concentrações de extrato variando de 512 a $8 \mu \mathrm{g} / \mathrm{mL}$ e DMSO para $5 \%$ de concentração.

\subsection{Meios de Cultura e Microrganismos}

Foram utilizados nos ensaios biológicos os seguintes meios de cultura: Agar Heart Infusion - HIA (Difco Laboratories Itda.), Brain Heart Infusion Broth - BHI (concentração indicada pelo fabricante a $10 \%$ ). Todos os meios de cultura foram preparados segundo as especificações do fabricante e esterilizados em autoclave.

Os microrganismos utilizados nos testes foram obtidos através do Instituto Nacional de Controle de Qualidade em Saúde (INCQS) da Fundação Oswaldo Cruz, Ministério da Saúde. Foram utilizadas linhagens padrão de bactérias Escherichia coli ATCC 10536 e 8539; Staphylococcus aureus ATCC 25923 e 6538 e multirresistentes da espécie Escherichia coli 27 e Staphylococcus aureus 358.

\subsection{Preparo e Padronização de Inóculos Bacterianos}

Culturas de bactérias foram mantidas a $4^{\circ} \mathrm{C}$ em Heart Infusion Agar (HIA). Antes dos testes, as linhagens foram repassadas para o meio citado e incubadas a $35^{\circ} \mathrm{C}$ por 24 horas. As linhagens repicadas que foram testadas foram inoculadas em Caldo Brain Heart Infusion $(\mathrm{BHI})$ e incubadas na mesma situação antes do teste. Suspensões com crescimento bacteriano passou pelo processo de diluição até a obtenção de $105 \mathrm{cels} / \mathrm{mL}$ (MENDONÇA et al., 2016). 


\subsection{Determinação da Concentração Inibitória Mínima (CIM)}

Os ensaios para determinação da CIM dos extratos metanólico e hexânico foram efetuados através do Método de Microdiluição em Caldo, com concentrações variando de 512 a $8 \mu \mathrm{g} / \mathrm{mL}$. As suspensões bacterianas previamente padronizadas foram diluídas na proporção 1:10 em Caldo BHI 10\% para obtenção da concentração final de 105céls/mL(19). Este método utiliza pequenos volumes de meio e de soluções preparadas a partir dos extratos, distribuídos em cavidades de microplacas estéreis. As soluções de testes foram preparadas em concentração dobrada $(1024 \mu \mathrm{g} / \mathrm{mL})$ em relação à concentração inicial definida e volumes de $100 \mu \mathrm{L}$, posteriormente, foram diluídas seriadamente 1:2 em caldo $\mathrm{BHI} 10 \%$. Em cada cavidade com $100 \mu \mathrm{L}$ do meio de cultura conterá amostra de suspensão bacteriana diluída na proporção 1:10. Controles negativos com o meio de cultura, controles positivos (meio + inoculo) e controles de inibição utilizando antimicrobianos em concentração de 512 a $8 \mu \mathrm{g} / \mathrm{mL}$ foram incluídos nos ensaios. As placas preenchidas ficaram incubadas a $35^{\circ} \mathrm{C}$ por 24 horas (NCCLS, 2000).

Para evidenciar a CIM das soluções frente as linhagens bacterianas, foi preparada uma solução indicadora de Resazurina sódica (Sigma) em água destilada estéril na concentração de 0,01\% (p/v). Após a incubação, $20 \mu \mathrm{L}$ da solução indicadora foram adicionados em cada cavidade e as placas foram passadas por um período de incubação de 20 minutos em temperatura ambiente, realizado em triplicata. A mudança de coloração azul para rosa devido à redução da Resazurina indica o crescimento bacteriano (JAVADPOUR et al., 1996; NCCLS, 2000), auxiliando a visualização da CIM, definida como a menor concentração capaz de inibir o crescimento microbiano, evidenciado pela cor azul inalterada.

\subsection{Avaliação moduladora de aminoglicosídios}

Para avaliar os extratos como moduladores da ação antibiótica e verificar sua atuação em sistemas de efluxo ativo, a CIM de antibióticos da classe dos aminoglicosídeos (amicacina e gentamicina) foram avaliados na presença e na ausência dos extratos em microplacas estéreis, descrita em Sato et al. (2004) e Matias et al. (2010). Todos os antibióticos testados foram obtidos junto a Sigma.

Os extratos foram misturados em caldo BHI 10\% em concentrações subinibitórias, obtidas e determinadas após a realização do teste de avaliação da CIM. A preparação das 
soluções de antibióticos realizar-se com a adição de água destilada estéril em concentração dobrada $(5000 \mu \mathrm{g} / \mathrm{mL})$ em relação à concentração inicial definida e volumes de $100 \mu \mathrm{L}$ diluídas seriadamente $1: 2$ em caldo BHI 10\%. Cada cavidade com $100 \mu \mathrm{L}$ do meio de cultura conteve a suspensão bacteriana diluída (1:10). Os mesmos controles utilizados na avaliação da CIM para os extratos foram utilizados (TINTINO et al., 2015). As placas preenchidas no sentido alfabético foram realizadas em triplicata e incubadas a $35^{\circ} \mathrm{C}$ por 24 horas e a leitura evidencia-se pelo uso de Resazurina sódica como citado anteriormente (PALOMINO et al., 2002).

\subsection{Análise Estatística}

Os resultados dos ensaios foram feitos em triplicata, e expressos como a média geométrica. A análise estatística foi aplicada à análise de variância de duas vias seguida pelo teste de Bonferroni utilizando o software GraphPad Prism 6.0.

\section{RESULTADOS E DISCUSSÃO}

Os resultados dos ensaios foram feitos em triplicata, e expressos como a média geométrica. A análise estatística foi aplicada à análise de variância de duas vias seguida pelo teste de Bonferroni utilizando o software GraphPad Prism 6.0.

Tabela 1. Concentração inibitória mínima $(\mathrm{CIM})(\mu \mathrm{g} / \mathrm{mL})$ dos extratos metanólico e hexânico de Eugenia uniflora $L$.

\begin{tabular}{lcccc}
\hline Extratos & EC 27 & EC- ATCC & SA 358 & SA-ATCC \\
\hline EMEU & $\geq 1024$ & $\geq 1024$ & $\geq 1024$ & $\geq 1024$ \\
EHEU & $\geq 1024$ & $\geq 1024$ & $\geq 1024$ & $\geq 1024$ \\
\hline EMEU - Extrato metanólico de Eugenia uniflora L.; EHEU - Extrato hexânico de Eugenia \\
uniflora L.; EC - Escherichia coli; SA - Staphylococcus aureus &
\end{tabular}




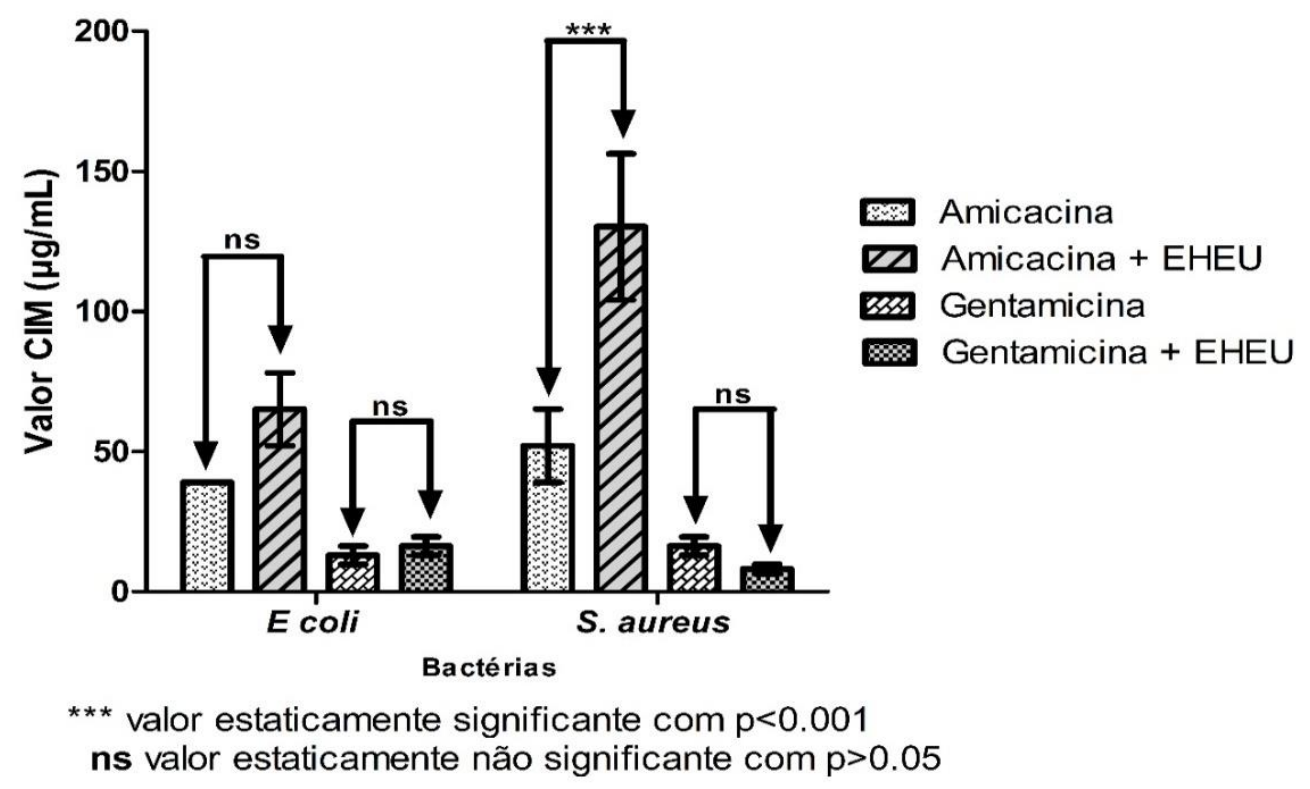

Gráfico 1. Concentração inibitória mínima $(\mu \mathrm{g} / \mathrm{mL})$ de aminoglicosídeos na ausência e presença do EHEU frente a Escherichia coli 27 e Staphylococcus aureus 358.

O extrato hexânico mostrou um resultado antagonista para a amicacina e gentamicina, assim, não apresentou positivamente modulação para as cepas de bactérias Escherichia coli e Staphylococcus aureus (Gráfico 2).

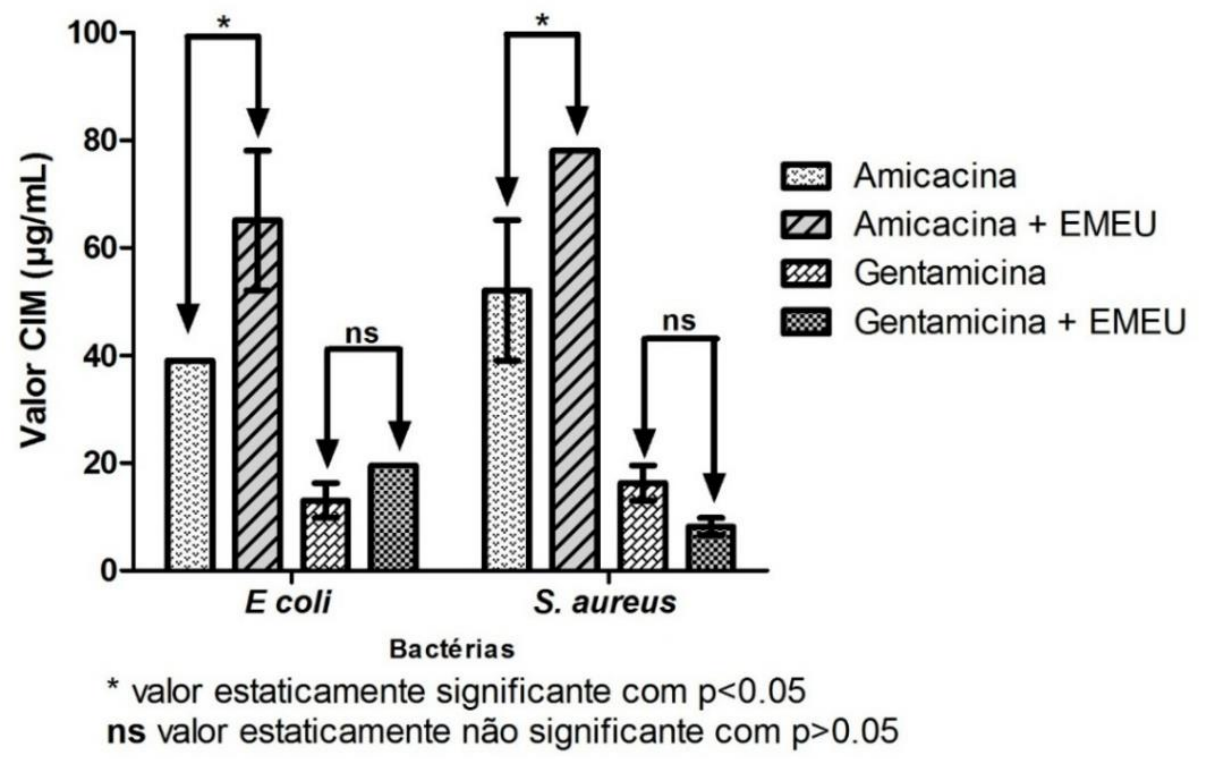

Gráfico 2. Concentração inibitória mínima $(\mu \mathrm{g} / \mathrm{mL})$ de aminoglicosídeos na ausência e presença do EMEU frente a Escherichia coli 27 e Staphylococcus aureus 358. 
TABELA 2. Prospecção fitoquímica dos extratos metanólico e hexânico de Eugenia uniflora L.

\begin{tabular}{llllllllllllll}
\hline EXTRATO & 1 & 2 & 3 & 4 & 5 & 6 & 7 & 8 & 9 & 10 & 11 & 12 & 13
\end{tabular}

\begin{tabular}{|c|c|c|c|c|c|c|c|c|c|c|c|c|}
\hline EMEU & - & & - & - & + & + & + & - & - & - & - & - \\
\hline EHEU & - & - & - & - & + & + & + & - & - & - & + & - \\
\hline
\end{tabular}

1-Fenóis; 2-Taninos Pirogálicos; 3-Antacioninas; 4-Antacianidinas; 5-Flavonas; 6-Flavonóis; 7-Xantonas; 8Chalconas; 9-Auronas; 10-leucoantocianidinas; 11-Catequinas; 12-Flavonas; 13- Alcalóide; (+) Presença; (-) Ausência. EHEU- Extrato Hexânico de Eugenia uniflora L.; EMEU- Extrato Metanólico de Eugenia uniflora L

De acordo com a tabela 2, foi observado nos extratos metanólico e hexânico a presença de compostos isolados de interesse medicinal. No qual, em um estudo foi relatado que a presença de flavonóides e taninos são bem conhecidas por apresentarem propriedades como supressores de radicais peroxila, no qual devem contribuir para a atividade antioxidante observada. Os taninos são classificados como estruturas polares, que apresentam um alto peso molecular, no qual, tem sua absorção pelo trato digestivo provavelmente dificultada (NÓBREGA, 2015).

Esses compostos estão associados na ação de processos anti-inflamatórios, como os flavonoides que já foi relatado em outros estudos (TINTINO et al., 2015). As flavonas além da ação em processos anti-inflamatórios, tem função antioxidante e antibacteriana (COUTINHO, MUZITANO e COSTA, 2009). Esses compostos secundários também auxiliam na ação dos antibióticos (SANTANA et al., 2016).

Após a realização dos testes com os extratos metanólico e hexânico, foram obtidos resultados de $\leq 1024 \mu \mathrm{g} / \mathrm{mL}$ sobre a Concentração inibitória mínima (CIM), assim, indicando que não apresentou atividade antibacteriana significante, portanto, esses extratos não são capazes de inibir o crescimento bacteriano das cepas de bactérias testadas, sendo um fato também relatado pelo extrato de Eugenia uniflora L. frente a atividade antibacteriana de Escherichia coli em estudos anteriores (NÓBREGA et al., 2016) e Castro et al. (2010) sobre Citrus limon L. e Sicana odorífera L.

Porém, outros estudos realizados expressaram sinergismo sobre os produtos naturais a atividade antibacteriana, em que foi possível reduzir a CIM das bactérias testadas, como o estudo realizado com as folhas de Kalanchoe pinnata (SANTANA et al., 2016), e também no teste da avaliação antibacteriana de Baccharis Trimera (Less.) (CARVALHO et al., 2013). Essa associação acontece pela inibição da bomba de efluxo, 
pois cada bomba tem afinidade por um substrato antimicrobiano, em que reverte a resistência bacteriana (NEVES, MAMIZUKA e LEVY, 2011) e as bactérias utilizam essas bombas em forma de auxílio na sua sobrevivência (LOPES, 2009).

Os extratos de Eugenia uniflora L. não foram eficazes na modulação da atividade de bactérias multirresistentes, no qual se teve diminuição da concentração dos antibióticos, que portanto, resultou um antagonismo sobre a inibição do crescimento, como também foi constatado nos testes de Schinus terebinthifolius raddi, Hymenaea courbail L., Beta vulgaris spp (SILVA, 2014; SALES et al., 2015; CRUZ et al., 2016). Consequentemente, os compostos quelantes presentes nos antimicrobianos como também nos extratos de produtos medicinais, pode trazer diminuição no efeito de ambos ${ }^{(11)}$.

\section{CONCLUSÃO}

Conclui-se que ao fazerem o uso de Eugenia uniflora L. juntamente com antibióticos testados, pode ter diminuição do efeito do mesmo, isto como foi apresentado na avaliação in vitro, assim, tornando o tratamento mais difícil. Desta forma torna- se importante o conhecimento da combinação de antibióticos com produtos naturais, pois outros podem apresentar os mesmos efeitos que este, sabendo que nem todos podem trazer benefícios, desmistificado a teórica de que o que é natural não faz mal. Portanto, este estudo serve de referência para outros estudos.

\section{REFERÊNCIAS}

ASSIS, A. L. A. Secagem, Embalagem e Armazenamento de Folhas de Pitangueira, Curitiba-PR, 05 Dezembro 2012. Mestrado [Programa de Pós-Graduação em Agronomia] - Universidade Federal do Paraná.

AURICCHIO, M. T.; BACCHI, E. M. Folhas de Eugenia uniflora L. (pitanga: propriedades farmacobotânicas, químicas e farmacológicas. Rev. Inst. Adolfo Lutz, v. 62, n. 1, p. 55-61, 2003.

AURICCHIO, M. T.; BUGNO, A.; BARROS, S. B.; BACCHI, E. Atividades antimicrobiana e antioxidante e toxicidade de Eugenia uniflora. Latin American Journal of Pharmacy, v. 26, n. 1, p. 76, 2007. 
BAGETTI, M.; FACCO, E. M. P.; RODRIGUES, D. B.; VIZZOTTO, M.; EMANUELLI, T. Antioxidant capacity and composition of pitanga seeds. Revista Ciência Rural, Santa Maria - RS, v. 39, n. 8, p. 2504-2510, Novembro 2009.

BEZERRA, J. E. F.; LEDERMAN, I. E.; SILVA-JÚNIOR, J. D.; ALVES, M. A. Comportamento da pitangueira (Eugenia uniflora L.) sob irrigação na região do Vale do Rio Moxotó, Pernambuco. Revista Brasileira de Fruticultura. Jaboticabal - SP, v. 26, n. 1, p. 177-179, 2004.

BRASILEIRO, B. G.; PIZZIOLO, V. R.; RASLAN, D. S.; JAMAL, C. M.; SILVEIRA, D. Antimicrobial and cytotoxic activities screening of some Brazilian medicinal plants used in Governador Valadares district, Rev. Brasileira Ciências Farmacêutica.v.42, p.195-202, 2006.

CARVALHO, A. C. Plantas Medicinais e Fitoterápicos: Regulamentação Sanitária e Proposta de Modelo de Monografia para Espécias Vegetais Oficializadas no Brasil, 2011. Tese [Programa de Pós-Graduação Ciências da Saúde] - Universidade de Brasília.

CARVAlHO, R. S.; CARVALHO, F.; MIRANDA, V.; ALEIXO, Á.; MAGALHÃES, J.; SIQUEIRA, J.; ALVES, L. Avaliação in vitro da atividade antibacteriana de Baccharis trimera (LESS.) de (ASTERACEAE) frente as bactérias de importância médica. BBRBiochemistry and Biotechnology Reports, v. 2, n. 2esp, p. 45-47, 2013.

CASTRO, R. D. D.; FREIRES, I. D. A.; FERREIRA, D. A. D. H.; JOVITO, V. D. C.; PAULO, M. D. Q. Atividade antibacteriana in vitro de produtos naturais sobre Lactobacillus casei, 2010. IJD. International Journal of Dentistry, v. 9, n. 2, p. 74-77, 2010.

COUTINHO, M. A. S.; MUZITANO, M. F.; COSTA, S. S. Flavonoides: Potenciais agentes terapêuticos para o processo inflamatório. Revista Virtual de Química, v. 1, n. 3, p. 241 256, 2009.

CRUZ, A. J. F.; BRITO, I. P.; SOBRAL, M. A. F.; SOUSA, A. T. L.; ALVES, E. F.; ANDREZA, R. S.; FERREIRA, S. S.; COSTA, R. O.; FIGUEREDO, F. G.; GUEDES, T. T.; MACÊDO, R. O.; RIBEIRO, T. R. G.; LEANDRO, L. M. G.; OlIVEIRA, C. D. M.; TINTINO, S. R.; 
COSTA, M. S.; AQUINO, P. E. A. Avaliação da atividade antibacteriana e moduladora dos extratos metanólico e hexânico da folha de Allium cepa. Revista Ciencias de la Salud, vol. 14, n. 2, p. 191-200, 2016.

FIRMO, W. D. C. A.; MIRANDA, M. V.; COUTINHO, G. S. L.; SILVEIRA, L. M. S.; OLEA, R. S. G. Estudo Fitoquímico e Avaliação da Atividade Antibacteriana de Lafoensia pacari (Lythraceae). Revista Ciências Biológicas e da Saúde, v. 20, n. 1, p. 7-12, 2014.

JAVADPOUR, M. M.; JUBAN, M. M.; LO, W. C. J.; BISHOP, S. M.; ALBERTY, J. B.; COWELL, S. M.; BECKER, C. L.; MCLAUGHLIN, M. L. De novo antimicrobial peptides withlow mammalian cell toxicity. J. of medicinal chemistry, 39: 3107-3113, 1996.

JUNIOR, V. F. V.; PINTO, A. C.; MACIEL, M. A. M. Plantas medicinais: cura segura. Química nova, v. 28, n. 3, p. 519-528, 2005.

LOPES, H. V. Antibióticos, resistência e novos mecanismos de ação. Revista Panamericana de Infectologia, São Paulo - SP, v. 11, n. 2, p. 67-68, 2009.

MARINHO, M. G. V.; SILVA, C. C.; ANDRADE, L. H. C. Levantamento etnobotânico de plantas medicinais em área de caatinga no município de São José de Espinharas, Paraíba, Brasil. Revista Brasileira de Plantas Medicinais, Botucatu-PA, v. 13, n. 2, p. 170-182, 2010.

MATIAS, E. F. F.; SANTOS, K. K. A.; ALMEIDA, T. S.; COSTA, J. G. M.; COUTINHO, H. D. M. Enhancement of Antibiotic Activity by Cordia verbenacea DC. Latin American J. Pharmacy.v.29, p.1049-1052, 2010.

MATOS, F. J. A. Introdução à Fitoquímica Experimental. 2ª Ed. -Fortaleza: UFC. 1997.

MENDONÇA, A. T.; CARVAlHO, A. R.; FERREIRA, M. C.; JÚNIOR, M. C. R. A Utilização dos Extratos Hidroalcoólico e Alcoólico de Eugenia uniflora L. como agente antibacteriano. Revista da Universidade Vale do Rio Verde, Três Corações-MG, v. 14, n. 1, p. 826-833, 2016. 
NASCIMENTO, A. L. D. R. Ação Antimicrobiana do Extrato de Eugenia uniflora L. (Pitanga) sobre Staphylococcus Aureus, Pseudomonas aeroginosa e Escherichia coli. 2013. Monografia [Bacharelado em Farmácia] - Universidade federal da Paraíba.

NCCLS - National Committee For Clinical Laboratory Standards. Methods for dilution antimicrobial susceptibility tests for bacteria that grow aerobically. 5 ${ }^{\underline{a}}$ ed. Villanova, PA: NCCLS approved standard M7-A5, v. 20, n. 2, 2000.

NEVES, P. R.; MAMIZUKA, E. M.; LEVY, C. E.; LINCOPAN, N. Pseudomonas aeruginosa multirresistente: um problema endêmico no Brasil. Jornal Brasileiro de Patologia e Medicina Laboratorial, São Paulo - SP, v. 47, n. 4, p. 409-420, 2011.

NÓBREGA, F. P. Avaliação das atividades antimicrobiana e moduladora da resistência a antibióticos de extratos de Physalis angulata L. 2015. Monografia [Bacharelado em Farmáica] - Universidade Estadual da Paraíba.

PALOMINO, J. C.; MARTIN, A.; CAMACHO, M.; GUERRA, H.; SWINGS, J.; PORTAELS, F. Resazurin microtiter assay plate: simlpe and unexpensive method for detection of drug resistance in Mycobacterium tuberculosis. Rev. Antimicrobial agents and chemotherapy, 46: 2720-2722, 2002.

ROCHA, D. P.; PINTO, G. F.; RUGGIERO, R.; OLIVEIRA, C. A.; GUERRA, W.; FONTES, A. P. S.; TAVARES, T. T.; MARZANO, I. M.; PEREIRA-MAIA, E. C. Coordenação de metais a antibióticos como uma estratégia de combate à resistência bacteriana. Revista Química Nova, v. 34, n. 1, p. 111-118, 2011.

SALES, G. W. P.; BATISTA, A. H. M.; ROCHA, L. Q.; NOGUEIRA, N. A. P. Efeito antimicrobiano e modulador do óleo essencial extraído da casca de frutos da Hymenaea courbaril L. Revista de Ciências Farmacêuticas Básica e Aplicada, v. 35, n. 4, 2015.

SANTANA, P. S.; ANDREZA, R. S.; LEITE, V. I.; SOUSA, P. C. V.; ALVES, A. A.; TINTINO, S. R.; OliVEIRA, C. D. M.; FIGUEREDO, F. G.; ROCHA, G. G. G.; MARTIN, A. L. A. R.; PEREIRA, B. S.; COSTA, R. O.; RODRIGUES, F. A. P.; LEANDRO, L. M. G.; AQUINO, P. E. A. Efeito antibacteriano e antifúngico de extratos etanólico, hexânico e metanólico a partir 
de folhas de Kalanchoe pinnata (Lam.). Biota Amazônia Open Jounal System, Macapá, v.6, n.1, pag. 64-69, 2016.

SANTOS, A. L.; SANTOS, D. O.; FREITAS, C. C.; FERREIRA, B. L. A.; AFONSO, I. F.; RODRIGUES, C. R.; CASTRO, H. C. Staphylococcus aureus: visitando uma cepa de importância hospitalar. Jornal Brasileiro de Patologia e Medicina Laboratorial, São Paulo - SP, v. 43, n. 6, p. 413-423, 2007.

SATO, Y.; SHIBATA, H.; ARAI, T.; YAMAMOTO, A.; OKIMURA, Y.; ARAKAKI, N.; HIGUTI, T. Variation in synergistic activity by flavone and its related compounds on the increased susceptibility of various strains of methicillin - resistant Staphylococcus aureus to $\beta$ - lactam antibiotics. International J. of Antimicrobial Agents, v. 24, p. 28-35, 2004.

SILVA, F. R. N. Atividade moduladora do extrato etanólico da Schinus terebinthifolius raddi sobre drogas antimicrobianas, 2014. Monografia [Bacharelado em Farmácia] Universidade Estaduel da Paraíba.

SOARES, E. C. D. L. Isolamento de Endofíticos de Eugenia Uniflora L. (pitanga) e avaliação da bioatividade, Recife-PE, 2011. Dissertação [Programa de Pós-Graduação em Ciências Farmacêuticas] - Universidade Federal de Pernambuco.

SOUZA, E. C.; MARTINEZ, M. B.; TADDEI, C. R.; MUKAI L, G. A. E.; RACZ, M. L.; SILVA, L.; EJZENBERG, B.; OKAY, Y. Perfil etiológico das diarreias agudas de crianças atendidas em São Paulo. Jornal de Pediatria, São Paulo-SP, v. 77, n. 1, p. 31-37, 2002.

TINTINO, S. R.; SOBRA, M. A. F.; ANDREZA, R. S.; ALVES, E. F.; CRUZ, A. J. F.; SOUSA, A. T. L.; OlIVEIRA, C. D. M.; LEANDRO, L. M. G.; AQUINO, P. E. A.; LIMA, L. F. Atividade antibacteriana e moduladora in vitro de extrato metanólico e hexânico de Beta vulgaris spp. (Linnaeus). Revista Cubana de Plantas Medicinales. Habana, v.21, n 1, 2015.

ZIMERMAN, R. A. Uso indiscriminado de antimicrobianos e resistência microbiana. Uso racional de medicamentos, temas selecionados, №3. Ministério de Salud, Brazil, 2010. 